\title{
Closed Microsurgery for the Sequelae of Neovascularisation from Veno-Occlusive Retinopathies
}

\author{
C. R. JAMES, P. M. JACOBS, P. K. LEAVER and D. McLEOD \\ London
}

\begin{abstract}
Summary
Our experience of closed microsurgery for vitreous haemorrhage and/or traction retinal detachment complicating extraretinal neovascularisation after retinal vein occlusion or Eales' and Behçet's periphlebitis is discussed. Many of these eyes represented a relatively simple management problem, but the visual outcome was often compromised by intrinsic macular damage. Some eyes had complicated vitreoretinal relationships which presented unexpected technical difficulties, while persisting retinal ischaemia posed the risk of rubeosis iridis or post-operative vitreous haemorrhage unless scatter endophotocoagulation was used.
\end{abstract}

Closed microsurgery for the sequelae of extraretinal neovascularisation is performed most commonly in patients with diabetes mellitus, and its efficacy is now well established. However, retinal capillary closure, ischaemia and neovascularisation (with the same complications of vitreous haemorrhage, retinal detachment and rubeosis iridis) also occur in patients with branch and central retinal vein occlusion (RVO), Eales' disease and Behçet's disease. In this report, we present a retrospective analysis of the results of microsurgical intervention in patients suffering from these complications.

\section{Material and Methods}

Forty-nine eyes (of 46 patients) undergoing closed microsurgery in the Surgical Vitreoretinal Unit of Moorfields Eye Hospital between 1976 and 1985 were the subject of this study. Twenty eyes had neovascularisation secondary to RVO (twelve with superotemporal branch RVO; four with inferotemporal branch RVO and four with central RVO).
Neovascularisation secondary to Behçet's disease (confirmed by a physician) was present in three eyes. In the remaining 26 eyes of 23 patients (three patients underwent bilateral surgery) a diagnosis by exclusion of Eales' disease was made after full medical examination and investigation had ruled out other aetiologies; the male:female ratio in this sub-group was 17:6.

Each patient was subjected to a detailed preoperative assessment including visual acuity, prehaemorrhage acuity and macular status (if known), and presence or absence of a relative afferent pupillary defect. Particular note was also made of lens opacities, rubeosis iridis, raised intraocular pressure and ophthalmoscopically visible retinal detachment. B-scan ultrasound examination was performed in eyes where vitreous haemorrhage or lens opacification obscured retinal detail (Fig. 1), but electrodiagnostic assessment was not performed. Of the 49 eyes, 25 had vitreous haemorrhage alone, three had macular retinal detachment alone (Fig. 2), 17 had vitreous haemorrhage and a retinal detachment (of which 13 involved the macula), and four had vitreous haemorrhage with elevated intraocular pressure that was felt to be 
erythroclastic in origin. Five eyes of patients with Eales' disease had pre-operative rubeosis iridis.

The surgical objectives included removal of axial haemorrhagic gel, separation of attached vitreous cortex, circumcision of vitreoretinal adhesions, dissection of fibrovascular epiretinal membranes and identification and treatment of any retinal breaks. When xenon-arc endophotocoagulation (and later endolaser photocoagulation) became available, scatter photocoagulation of ischaemic retina (either sectorial or generalised) was also performed (including half the eyes with branch RVO and twothirds of the eyes with Eales' vasculitis) (Fig. 3). In four of the 49 eyes, lensectomy was also carried out at the time of vitreous surgery. In one eye silicone oil was injected after deliberate giant peripheral retinotomy.

All patients were followed post-operatively for at least six months (or for six months after reintervention when this was necessary). The following reinterventions were performed: ten detachment procedures, of which three involved silicone oil injection; six cataract extractions; two 'washouts' plus endolaser; two trabeculectomies; two sectorial photocoagulation procedures with argon laser and one enucleation. The overall follow-up interval was two years on average (range six months to ten years).

\section{Results}

\section{Technical Outcome}

Forty-five eyes (92 per cent had a clear vitreous cavity and an attached retina six months after initial closed microsurgery or after reintervention (Figs. 2, 3 and 4).

\section{(a) Post-vitrectomy haemorrhage}

This occurred to a significant degree in four eyes. In two eyes with branch RVO (neither of which had received endophotocoagulation), no further bleeding occurred after post-operative laser treatment. In two eyes of patients with Eales' disease (both of which had received endophotocoagulation) a 'washout' procedure was necessary, supplemented by further endophotocoagulation. There were no chronic vitreous cavity haemorrhages.

\section{(b) Post-operative retinal detachment}

This occurred in ten eyes, six of which were successfully reattached with further surgery. The retinal detachment in two eyes failed to respond to further surgery, and in two eyes no retinal surgery was performed. Four of these detachments were due to iatrogenic breaks in ischaemic atrophic retina (two branch RVO eyes and two eyes with Eales' perivasculitis); three detachments reflected failure to achieve complete separation of non-detached posterior vitreous cortex or complete circumcision of peripheral vitreoretinal traction (two eyes with Eales' disease; one with branch RVO). In the remaining three eyes (all with branch RVO), an unrecognised entry-site break, an unrecognised peripheral break, and distant proliferative vitreoretinopathy at the posterior border of the vitreous base (with associated break formation) were each responsible for detachment. Of the four eyes with persistent post-operative retinal detachment, one eye became phthisical and one was enucleated for rubeotic glaucoma.

\section{(c) Macular Pucker}

Of eight eyes with macular pucker at surgery, only three were electively peeled. Three further eyes developed macular pucker after surgery.

\section{(d) Rubeosis Iridis}

In the five eyes with Eales' disease and pre-operative rubeosis, scatter endophotocoagulation was performed and the rubeosis was substantially reduced or eliminated in each case. Although none of the eyes with RVO had pre-operative rubeosis, rubeosis appeared after surgery in one eye with branch RVO which had not undergone endophotocoagulation. This responded to post-operative laser treatment. Rubeosis iridis also complicated persistent post-operative retinal detachment in two eyes.

\section{(e) Erythroclastic Glaucoma}

Of the four eyes with vitreous haemorrhage and ocular hypertension associated with erythroclasts in the anterior chamber, there was a marked reduction in intraocular pressure after surgery in two eyes so that oral Diamox therapy (but not topical anti-glaucoma treatment) could be discontinued. Early glaucoma drainage surgery was necessary in one of the remaining eyes.

\section{(f) Cataract}

Some degree of lens opacification was common preoperatively, occurring in 50 per cent of eyes with RVO and 28 per cent of eyes with Eales' or Behçet's disease. In addition to the four eyes undergoing lensectomy at the time of vitreous surgery, six eyes had post-operative cataract surgery. In a further 14 eyes, pre-existing lens opacities became more pronounced, or lenses that were previously clear developed opacities despite the fact that treatment in only half these eyes included intraocular tamponade. 

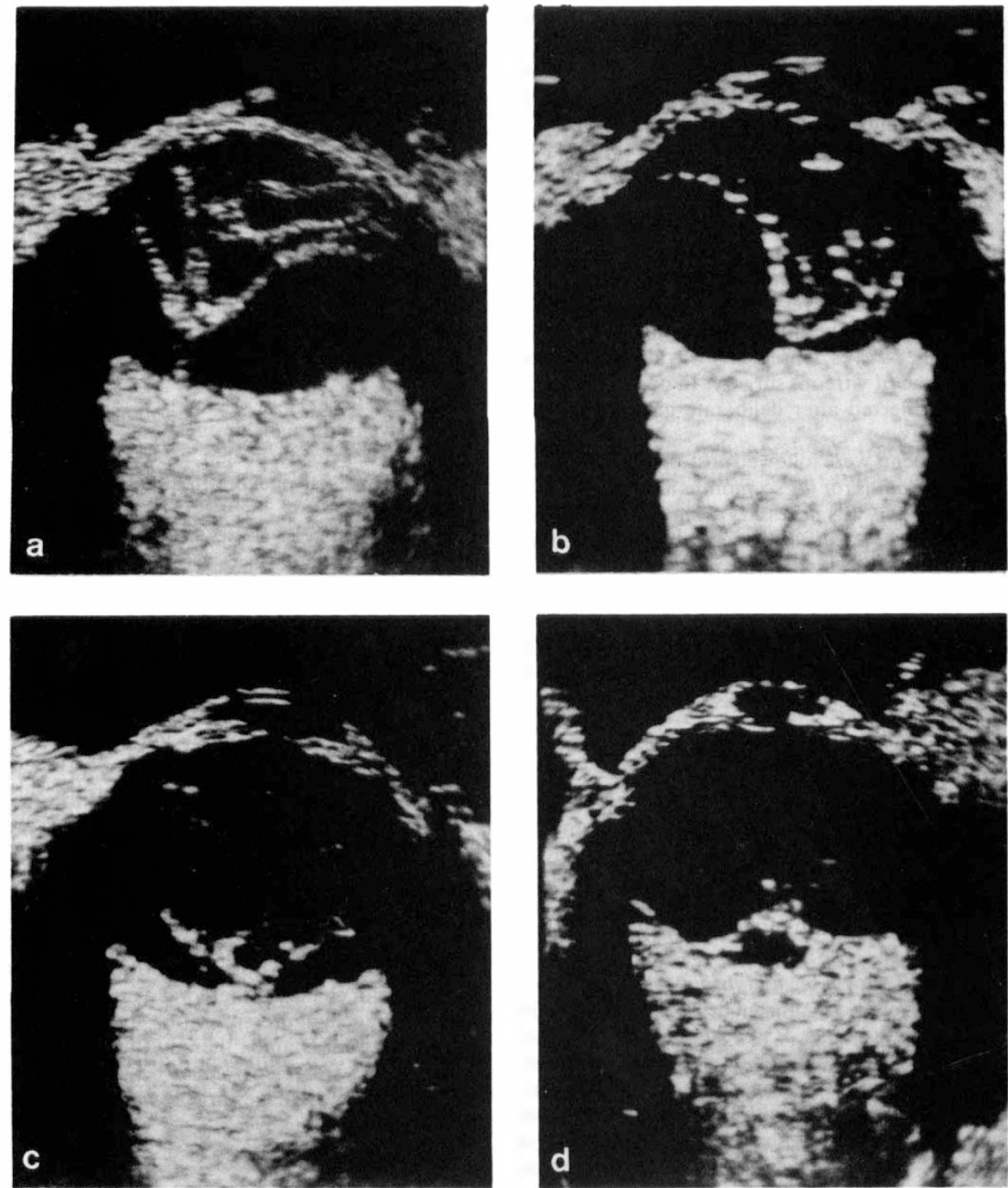

Fig. 1. B-scan ultrasound in eyes with vitreous haemorrhage.

(a) Focal vitreoretinal adhesion.

(b) Multiple vitreoretinal adhesions.

(c) Wide vitreoretinal adhesion to fibrovascular epiretinal membrane.

(d) Localised posterior traction retinal detachment.

\section{Visual Outcome}

Forty-three eyes showed an improvement in visual acuity at six months after surgery (or six months after reintervention) (Fig. 5). Vision in four of the six eyes, that did not improve post-operatively, was reduced to perception of light or blindness by persistent retinal detachment. Two other eyes failed to 

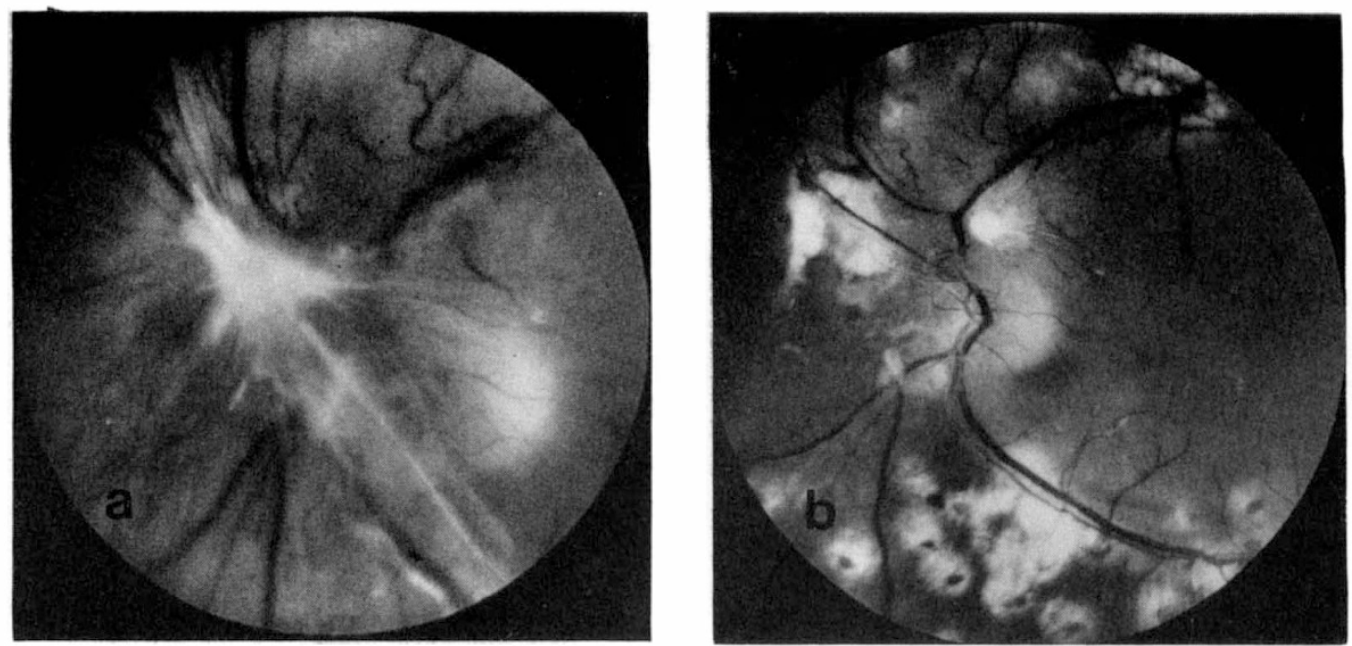

Fig. 2. Fundus photographs of left eye of patient with Eales' disease.

(a) Traction macular detachment from fibrovascular epiretinal membrane superonasal to optic disc (acuity 6/36).

(b) Retinal reattachment after vitrectomy and membrane dissection (acuity 6/18).

improve; one of these had macular ischaemia and remained at counting fingers vision, and the other dropped from $6 / 9$ to $6 / 12$ after the retinal detachment on presentation was successfully reattached. No eye with RVO achieved a post-operative acuity better than $6 / 12$, in contrast to 10 out of 26 eyes of patients with Eales' or Behçet's disease which regained excellent acuity. In each of the eyes with a post-operative acuity of $6 / 12$ or less, there was significant macular pathology (Table I). Although some degree of lens opacification affected the ultimate acuity in many cases, it was never primarily responsible for an acuity of $6 / 12$ or less.

The presence or absence of a pre-operative relative afferent pupillary defect (RAPD) was of some value in forecasting the visual outcome in the 17 eyes in which the fellow eye was completely normal. Of the eight eyes with a pre-operative RAPD, the maximum acuity achieved was only $6 / 12$, whereas of the nine eyes with no pre-operative RAPD, the minimum acuity achieved was $6 / 24$.

One patient with Behçet's disease and another patient with Eales' disease developed a fresh symptomatic periphlebitic lesion affecting a major venule, with associated capillary closure, in their fellow eyes within two months of vitrectomy and endolaser photocoagulation (Fig. 6).

\section{Discussion}

Eales' disease is an enigmatic diagnosis and probably represents a spectrum of, as yet undefined, conditions. Ever since 1880, when Henry Eales ${ }^{1,2}$ first drew attention to four young men with idiopathic 'recurrent retinal haemorrhages' in association with constipation and epistaxis, the clinical course of patients labelled with his name has been unpredictable. Eales recognised the complications of vitreous haemorrhage 'from venous radicles', rubeotic glaucoma and retinal detachment and went on to describe beautifully how, 'on the areas of detached retina, a branch of the retinal veins was invariably found, and more than once a many tailed opacity of the vitreous was found to be attached to the veins at the most bulging point of the detachment' ${ }^{2}$ Duke-Elder summarised the characteristic clinical picture of young men with recurrent retinal haemorrhages starting peripherally and moving centrally and noted visual loss secondary to retinitis proliferans, glaucoma and vitreous haemorrhage. He warned, however, against 'heroic measures such as the aspiration of the clouded vitreous' ${ }^{3,4}$ Of the 100 patients in his series, Donders ${ }^{5}$ noted retinitis proliferans in 66 per cent, retinal detachment in 19 per cent and recorded three enucleations for glaucoma. 

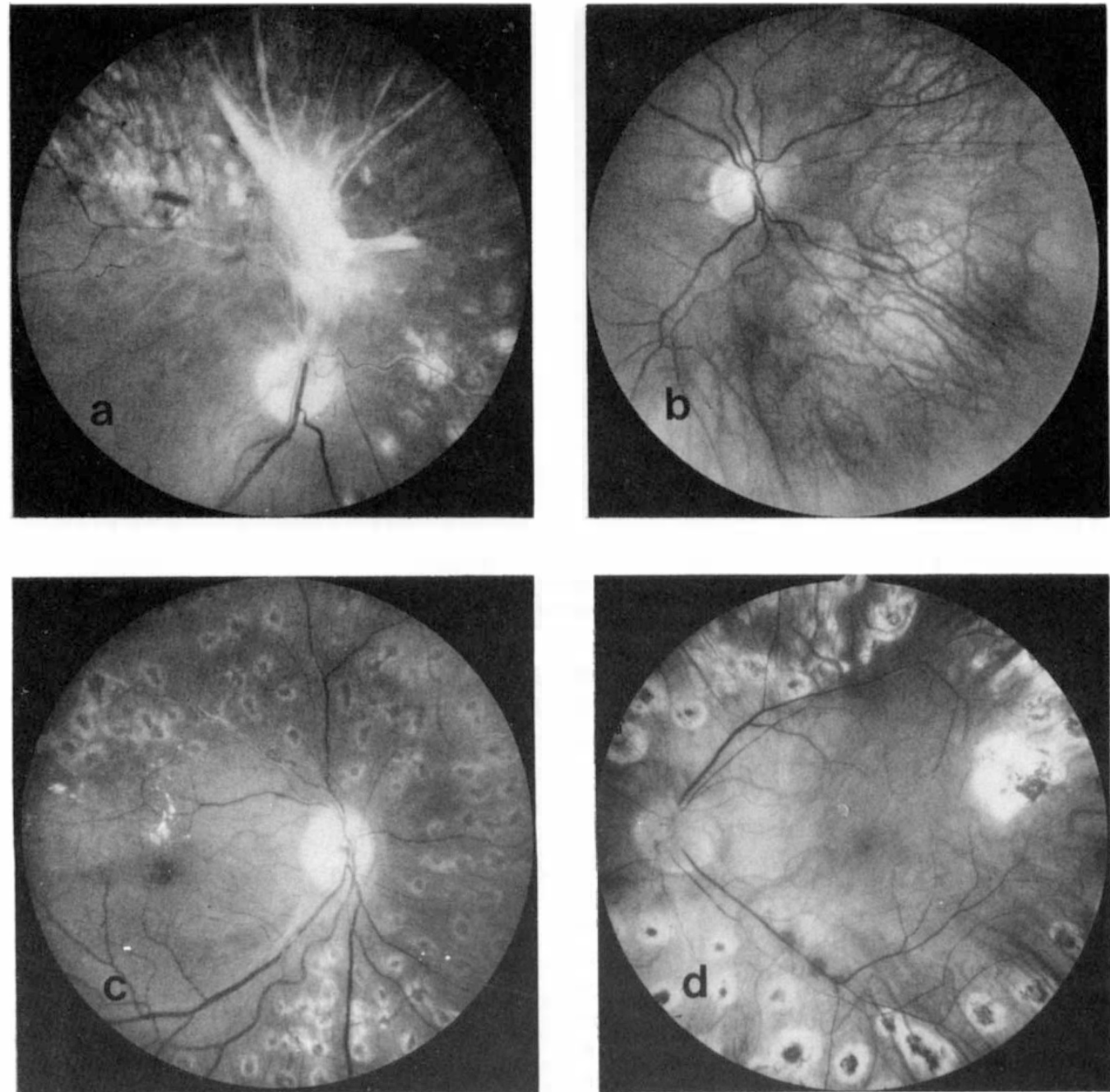

Fig. 3. Fundus photographs after closed microsurgery for vitreous haemorrhage.

(a) Reattachment of ischaemic macula in right eye with branch R.V.O.; sectorial endophotocoagulation (acuity 6/60).

(b) Reattachment and cryocoagulation of localised combined traction and rhegmatogenous detachment nasal to optic disc in right eye with central R.V.O. (acuity 6/60).

(c) Exudative maculopathy and scatter endophotocoagulation in right eye of patient with Behçet's disease (acuity 6/24).

(d) Macula after epimacular membrane peeling in left eye of patient with Eales' disease; scatter endophotocoagulation (acuity 6/12).

Spitznas et $a l^{6}$ noted retinal neovascularisation in 84 per cent, vitreous haemorrhage in 58 per cent and retinal detachment in 5 per cent of their series of 316 patients with 'avascular areas in the retinal periphery'. In contrast to these findings, Elliott ${ }^{7}$ recorded a high incidence of spontaneous resolution and noted that only one patient in his series of 135 patients, followed for many years, required blind registration. A similar picture of peripheral capillary closure as a result of periphlebitis has been described in Behçet's disease. . $^{4,8}$

The risk of neovascularisation following branch RVO is more predictable ( 22 per cent-31 per cent), ${ }^{9,10,11,12}$ and the subsequent 

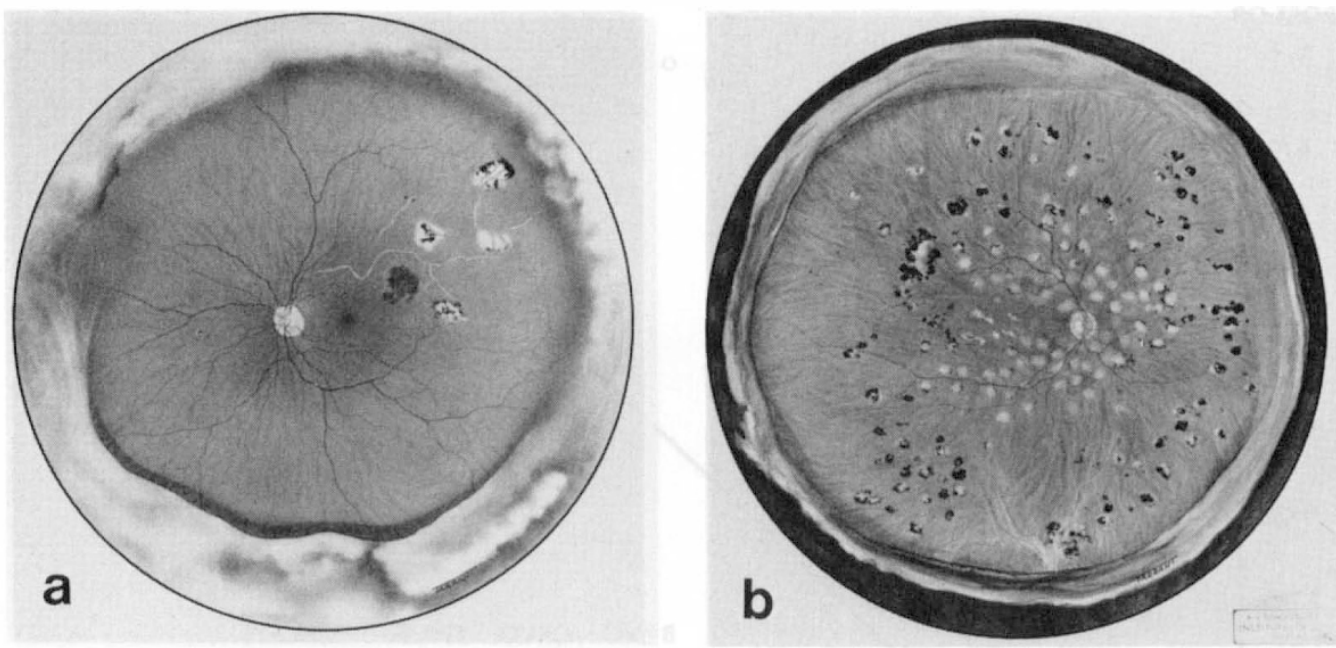

Fig. 4. Postvitrectomy fundus paintings of eyes with vitreous haemorrhage despite pre-haemorrhage photocoagulation.

(a) Superotemporal branch R.V.O. (left eye).

(b) Right eye of patient with Eales' disease.

risk of haemorrhage in an eye with neovascularisation is high (48 per cent- 91 per cent).$^{10,11,12}$ The risk of retinal detachment has been more difficult to establish; in our study, a third of the vitreous haemorrhages from branch RVO obscured an underlying retinal detachment. By contrast, eyes with ischaemic central RVO have a lower risk of extraretinal neovascularisation ( 10 per cent) though up to half of these may also develop a vitreous haemorrhage. ${ }^{12}$

Just as in diabetes, the incidence of vitreous haemorrhages and rubeosis in these ischaemic veno-occlusive retinopathies can be significantly reduced by photocoagulation. . $^{13,14,15}$ Systemic steroids and other immunosuppressives may also contribute in the management of vitreous haemorrhage from Eales' and Behçet's disease. ${ }^{4,8}$ However, there continue to be patients in whom it has not been possible to apply sufficient photocoagulation before vitreous haemorrhage or rubeosis supervene. In this series, we have shown that by using a microsurgical approach it is possible to remove vitreous haemorrhage, to reattach the retina, to cause rubeosis to regress and to improve vision in the majority of cases.

Two major factors determining the technical outcome are the pre-operative extent of vitreoretinal adhesion and retinal detach- ment, and the occurrence of iatrogenic tears in ischaemic atrophic retina. In branch RVO with vitreous haemorrhage alone, vitreous detachment was virtually complete in many cases, with only tenuous adhesions to fibrovascular tissue (perhaps reflecting the sectorial ischaemia and the age of the patients). Particular problems arose, however, in identification and circumcision of very peripheral vitreoretinal adhesions obscured behind a densely opaque peripheral gel frill. This observation is in keeping with the higher incidence of peripheral (as opposed to disc) neovascularisation after ischaemic branch RVO. ${ }^{11}$ Formation of iatrogenic breaks, or the possibility of completely isolating areas of vitreoretinal adhesion from the vitreous base, sometimes resulted in post-operative retinal detachment.

We found a wide variation in the degree of posterior vitreous detachment in eyes of patients with Eales' disease. In some, the posterior hyaloid face had completely separated from the retina apart from a single residual attachment to the optic disc; in others, the cortex remained attached to isolated posterior neovascular membranes or areas of traction retinal detachment. However, in two patients with vitreous haemorrhage and a flat retina, there was virtually no posterior vitreous 


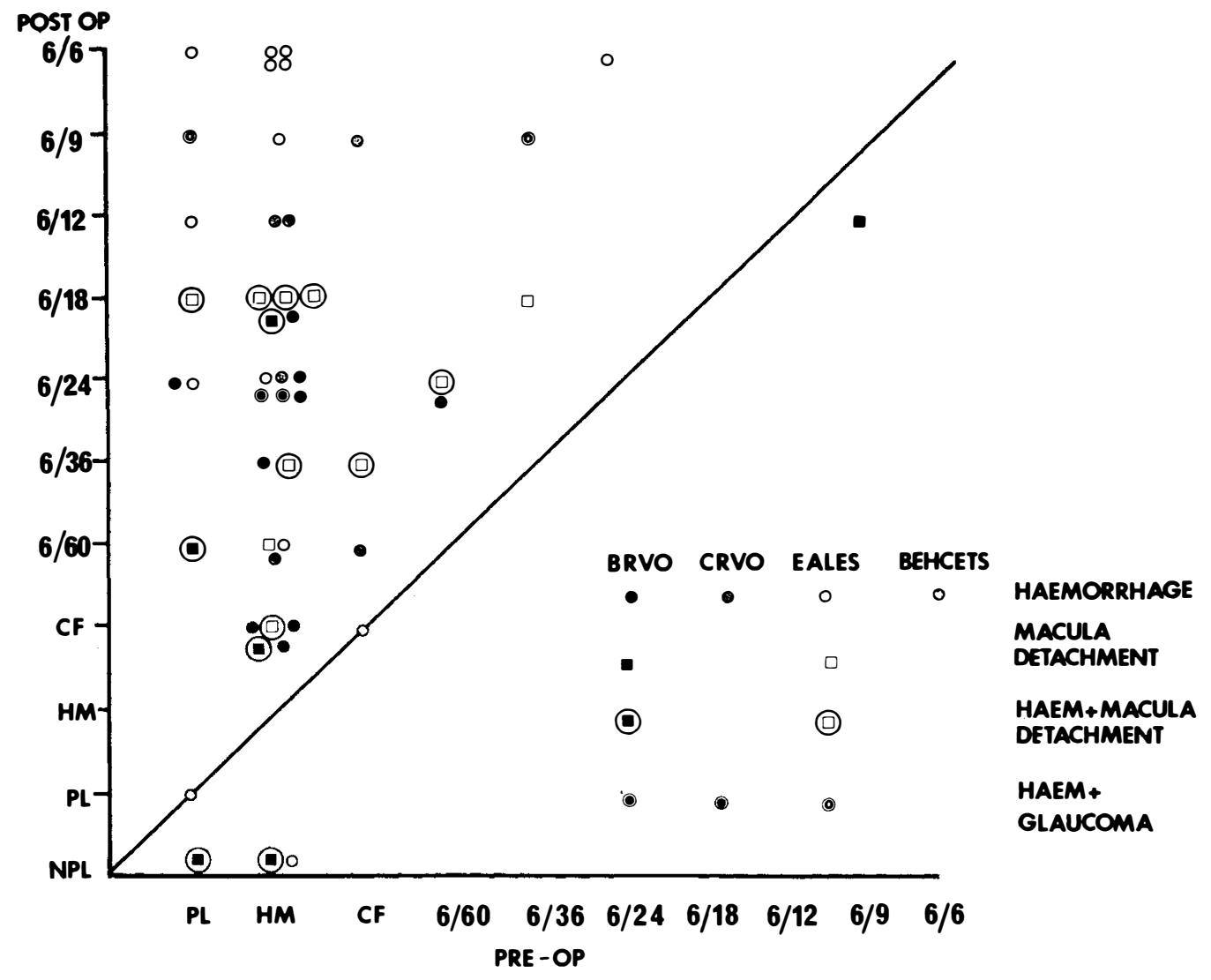

Fig. 5. Scattergram comparing preoperative acuity and postvitrectomy acuity in 49 eyes; each symbol represents one eye and symbols above the oblique line denote eyes with improved vision.

detachment, and failure to remove all cortical vitreous gel from the surface of the retina subsequently resulted in retinal detachment. Viscodelamination of attached cortical gel may improve the prognosis for such cases in the future. ${ }^{16,17}$

Some degree of pre-operative lens opacification was a very common finding in our patients and this was also the case in Michel's series of branch RVO eyes coming to vitrectomy. ${ }^{18}$ Rather than carrying out vitreolensectomy, we preferred to leave the lens intact wherever possible thus preserving the option of elective extracapsular cataract extraction with posterior chamber implant subsequently.

Pre-operative rubeosis iridis was present in five eyes with Eales' disease and regressed in
Table I Causes of acuity 6/12 or less

\begin{tabular}{lcc}
\hline \multicolumn{1}{c}{ Cases } & $\begin{array}{c}\text { Of 29 eyes } \\
\text { with Eales' } \\
\text { or Behçet's } \\
\text { periphlebitis }\end{array}$ & $\begin{array}{c}\text { Of 20 eyes } \\
\text { with branch or } \\
\text { central vein } \\
\text { occlusion }\end{array}$ \\
\hline $\begin{array}{l}\text { Following successful } \\
\text { macular } \\
\text { reattachment }\end{array}$ & 6 & 3 \\
$\begin{array}{l}\text { Exudative } \\
\text { maculopathy }\end{array}$ & 6 & 5 \\
$\begin{array}{l}\text { Ischaemic } \\
\text { maculopathy or } \\
\text { macular hole }\end{array}$ & 1 & 6 \\
$\begin{array}{l}\text { Macular pucker } \\
\text { Persistent total retinal } \\
\text { detachment }\end{array}$ & 4 & 4 \\
\hline \begin{tabular}{l} 
Total \\
\hline
\end{tabular} & 2 & 20 \\
\hline
\end{tabular}



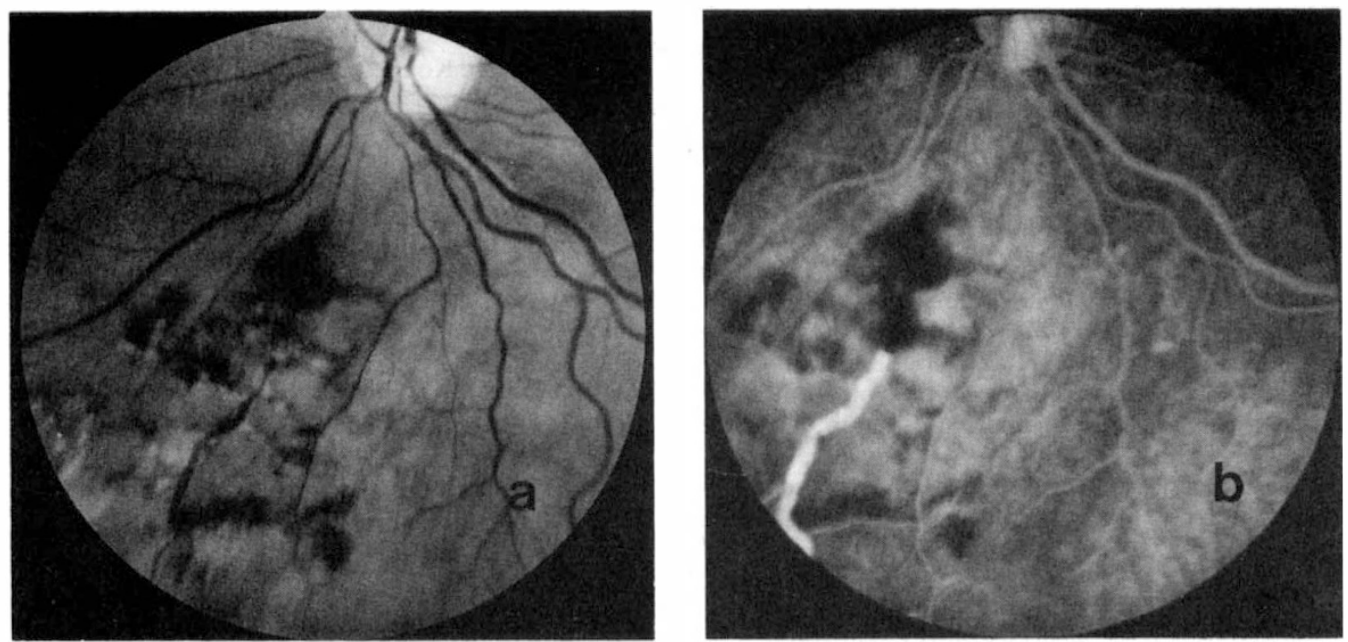

Fig. 6. Fellow eye of patient with Behçet's disease.

(a) Fundus photograph of sectorial haemorrhages and vasculitis inferonasal to optic disc.

(b) Fluorescein angiogram (late phase) demonstrating venous occlusion.

all five cases after pre-operative endophotocoagulation. In addition, our overall impression is that both post-operative rubeosis and the tendency to rebleeding are reduced by endophotocoagulation, in keeping with our experience of endophotocoagulation in diabetic vitreous haemorrhage. ${ }^{19}$

The most important factor affecting visual outcome was the state of the macula (Table I). Although many eyes with branch RVO recover an acuity of $6 / 6$, none of the eyes with this diagnosis in this series had a macula capable of more than 6/12. As such, our results are broadly comparable with those in Michels' series, ${ }^{18}$ bearing in mind that he excluded eyes with macular traction detachment and performed more lensectomies. The eyes of patients with Eales' and Behçet's disease had a more favourable visual outcome, 34 per cent achieving post-operative acuities of $6 / 6$ or $6 / 9$. Nevertheless, in the remaining eyes, macular damage was consistently present, in some cases reflecting involvement of the macular circulation by the underlying disease process.

In conclusion, when assessing a patient preoperatively, the most important technical considerations are the degree of posterior vitreous separation and retinal detachment present. Apart from removing haemorrhagic gel, the surgical objectives should include separation of the cortical vitreous face, treatment of pre-existing or iatrogenic breaks, and endophotocoagulation of ischaemic retina. As in diabetic vitrectomy, post-operative retinal detachment carries with it the risk of rubeosis, phthisis and possible enucleation. Some degree of macular embarrassment can be expected in eyes with branch RVO and in many eyes of patients with Eales' or Behçet's disease.

Against this rather pessimistic background, however, a third of patients with Eales' disease can nevertheless expect excellent post-operative vision (6/6-6/9) and vision in the 6/12-6/24 range can be anticipated in half the patients with branch RVO and a further third of patients with Eales' disease. Lower levels of post-operative vision may represent a worthwhile improvement for patients with an 'only eye', though the presence of a marked relatively afferent pupillary defect in a patient with branch RVO, vitreous haemorrhage and an attached macula, but with a normal fellow eye, is usually considered a contra-indication to surgery. Finally, provided an endophotocoagulation facility is available, rubeosis iridis can be reversed and in some cases of Eales' and Behçet's disease treatment with Diamox or steroids can be discounted.

We thank Miss M. Restori for the ultrasound 
studies, Miss L. Haslin and Miss H. Lucas for invaluable secretarial assistance, the Moorfields Audiovisual Department for the illustrations and the Help the Hospitals Charity for the endolaser.

\section{References}

${ }^{1}$ Eales H: Cases of retinal haemorrhage associated with epistaxis and constipation. Birmingham Medical Review, 1880, 9: 262-73.

${ }^{2}$ Eales H: Primary retinal haemorrhage in young men. The Ophthalmic Review 1882, 1: 41-6.

${ }^{3}$ Duke-Elder WS: In Textbook of Ophthalmology. Publisher: Henry Kimpton, London, 1940, 3: 2602-3.

${ }^{4}$ Duke-Elder WS and Dobree JH: In System of Ophthalmology. Publisher: Henry Kimpton, London 1967, 10: 218-36.

${ }^{5}$ Donders PC: Eales' disease. Doc Ophthalmol 1958, 12: 1-105.

${ }^{6}$ Spitznas M, Meyer-Schwickerath G. and Stephan B: The clinical picture of Eales' disease. Albrecht $v$. Graefes Arch. Klin. Exp. Ophthal. 1975, 194: 73-85.

${ }^{7}$ Elliot AJ: 30 year observation of patients with Eales' disease. Am. J. Ophthalmol. 1975, 80: 404-8.

${ }^{8}$ Page NGR, Thomson A and Geraint James D: Behçet's disease. Trans. Ophthalmol. Soc. UK 1982, 102: 174-6.

${ }^{9}$ Michels RG and Gass JDM: The natural course of retinal branch vein obstruction. Trans. Am. Acad. Ophthalmol. and Otolaryngol. 1974, 78: 166-77.

${ }^{10}$ Gutman FA and Zegarra $\mathrm{H}$ : The natural course of temporal retinal branch vein occlusion. Trans.
Am. Acad. Ophthalmol. and Otolaryngol. 1974, 78: $178-92$.

${ }^{11}$ Shilling JS and Kohner EM: New vessel formation in retinal branch occlusion. Br. J. Ophthalmol. 1976, 60: 810-15.

${ }^{12}$ Hayreh SS, Rojas P, Podhajsky P, Montague P and Woolson RF: Ocular neovascularization with retinal vascular occlusion-III. Ophthalmology 1983, 90: 488-506.

${ }^{13}$ Brain Vein Occlusion Study Group: Argon laser scatter photocoagulation for prevention of neovascularization and vitreous haemorrhage in branch vein occlusion. Arch. Ophthalmol. 1986, 104: $34-41$.

${ }^{14}$ Laatikainen L, Kohner EM, Khoury D. and Blach RK: Panretinal photocoagulation in central retinal vein occlusion: a randomised controlled clinical study. Br. J. Ophthalmol. 1977, 61: 741-53.

${ }^{15}$ Spitznas M, Meyer-Schwickerath G and Stephan B: Treatment of Eales' disease with photocoagulation. Albrecht v. Graefes Arch. Klin. Esp. Ophthal. 1975, 194: 193-8.

${ }^{16}$ Barry PJ, Hiscott PS, Grierson I, Marshall J and McLeod D: Reparative epiretinal fibrosis after diabetic vitrectomy. Trans. Ophthalmol. Soc. U.K. 1985, 104: 285-96.

${ }^{17}$ McLeod D and James CRH: Viscodelamination at the vitreo-retinal juncture in severe diabetic eye disease. (In press.)

${ }^{18}$ Oyakawa RT, Michels RG and Blase WP: Vitrectomy for nondiabetic vitreous haemorrhage. Am. J. Ophthalmol., 1983, 96: 517-25.

${ }^{19}$ Ficker LA, Passani F, Leaver PK and McLeod D: Xenon-arc endophotocoagulation during vitrectomy for diabetic vitreous haemorrhage. Graefe's Arch. Clin. Exp. Ophthal. 1986. (In press.) 